\title{
Women's status within the household as a determinant of maternal health care use in Nigeria
}

\author{
Olufunmilayo I Fawole, Ikeola A Adeoye
}

Epidemiology and Medical Statistics, Faculty of Public Health, College of Medicine, University of Ibadan, Nigeria.

\begin{abstract}
Background: Although gender inequality is often cited as a barrier to improving maternal health in sub-saharan Africa, there is lack of empirical data on how women's socio-cultural characteristics may influence use of health services in Nigeria. Objective: To describe how women's position in the household affects receipt of maternity care services.

Methods: Secondary data analysis of 10,052 and 4,590 currently married women aged 15 to 49 years from the 2008 Nigerian DHS who receive skilled antenatal and delivery care at least till pregnancy was done.

Results: Receipt of skilled delivery care was by $37.9 \%$ while, natal care was by $98.4 \%$. Education, residence and wealth index all significantly influenced receipt of maternal health care. Women who were involved in decision making on their own health $(\mathrm{aOR}=1.97 ; 95 \% \mathrm{CI}=1.88-2.06)$ and were employed throughout the year $(\mathrm{aOR}=1.11 ; 95 \% \mathrm{CI}=1.01-1.23)$ were more likely to receive skilled antenatal care, while those who justified physical intimate partner violence were less likely to receive both skilled antenatal care $(\mathrm{aOR}=0.92 ; 95 \% \mathrm{CI}=0.85-0.98)$ and delivery services (aOR $0.54 ; 95 \% \mathrm{CI} 0.33-0.87)$.

Conclusion: Interventions aimed at improving maternal care should promote women empowerment (decision making, self worth, educational and economic) and should involve partners.

Key words: women's position, women's status, skilled antenatal care, skilled delivery care, gender inequality in Africa, physical intimate partner violence
\end{abstract}

DOI: http://dx.doi.org/10.4314/ahs.v15i1.28

\section{Introduction}

Proper care during pregnancy and delivery is important for the health of both the mother and the baby, and is an indicator of the status of maternal and child health in the society. More than 600,000 women die due to childbirth or pregnancy related complications around the world annually ${ }^{1}$. The overwhelming majority of maternal deaths occur in developing countries ${ }^{2}$. Sub-saharan Africa and South Asia account for about $87 \%$ of global maternal deaths ${ }^{1}$. Africa has the highest maternal mortality ratio with an estimated average of 800 deaths per every 100,000 births. The lifetime risk of maternal

\section{Corresponding author:}

Olufunmilayo I Fawole

Dept of Epidemiology and Medical Statistics,

Faculty of Public Health, College of Medicine,

University of Ibadan, Nigeria

Email: fawoleo@ymail.com

Tel: 2348032180302

Fax: 2342413545 death in sub-Saharan Africa is 1 in 31 compared to 1 in 4,300 in developed regions ${ }^{1}$. Nigeria is solely responsible for close to $10 \%$ of these deaths. The estimated average maternal mortality rate in Nigeria is 1,000 for every 100,000 births however this figure varies according to regions of the country ${ }^{1,2,3}$. Based on the $2008 \mathrm{Ni}-$ geria Demographic and health survey, maternal mortality in Nigeria is estimated to be around 545 deaths per 100,000 births $^{4}$. For every maternal death, many more women suffer serious complications ${ }^{2}$.

A woman's death during pregnancy or childbirth is not only a health issue but also a matter of social injustice ${ }^{2}$ reflecting the failure of communities and governments to promote safe motherhood ${ }^{5,6}$. Maternal mortality is a reflection of women's place in society and their lack of access to social, health and nutrition services, and to economic opportunities ${ }^{1,2}$. Maternal mortality also reflects disparities in socio-economic development. Most of the victims of maternal deaths are women between the ages of 15 and 45 years ${ }^{7}$. However, major reasons for the higher risk in developing countries are the non-utilization of maternal health services by mothers as well as the poor quality care from health services ${ }^{8,9}$. 
Thus the causes of the vast majority of these deaths and complications are preventable ${ }^{5}$.

In seeking to redress these low levels of maternity care use in sub-saharan Africa, most research has focused on addressing the clinical issues related to maternal mortality, less attention has been paid to the social determinants of maternal deaths ${ }^{10,11,12}$. Only a few studies have explored ways in which gender roles and relations may operate to restrict women's access to health care during pregnancy, at the time of delivery and after delivery. These few studies explored the relationship between education and employment with reproductive variables such as abortion, fertility and family size ${ }^{13,14}$. Also, the association between women's socio cultural factors and contraceptive use was explored ${ }^{15,16}$. There is also literature on the links between spousal position or approval and contraceptive use, but these studies are all outdat$\mathrm{ed}^{16,17}$. However, only a few of these researchers examined whether and how dimensions of women's position are related to their use of maternal health care services in Africa. Thus the influence of socio cultural factors, such as women's position within the household on use of maternity services has not been critically explored.

It is widely asserted that increased gender equality is a prerequisite for achieving improvements in maternal health. The Millennium Development Goal (MDG) 3 aims to achieve gender equality and women empowerment. It is one MDG that makes it easier for all other MDGs, especially MDGs 4 and 5 to be achieved ${ }^{18}$. In most African countries, the low social status of women has been identified as a hindrance to progress toward national health and population policy targets ${ }^{1,2,3}$.

Although it can be assumed that greater equality within the household leads to higher use of maternal health care services, this has not been examined among Nigerian women. It is also unknown how intra-household relations affect access to health care, or which of the dimensions of women's position is most critical fo achieving increased use. Thus this study examined the influence of women's household position on the receipt of skilled antenatal and delivery care.

\section{Methodology}

Study design

The study was a secondary data analysis of the 2008 Nigeria Demographic and Health Survey (DHS) ${ }^{4}$. The study design was a national cross sectional survey. The One of the targets of national health policy is to reduce maternal mortality rate by three-quarters between 1990 and 2015. Currently the thrust of government efforts is to improve quality of care provided at health facilities, ensure proper management of major obstetric complications and build capacity of health care providers to provide skilled maternity care ${ }^{4,2}$

\section{Sample design}

This is a secondary data analysis of the 2008 Nationa Demographic and Health Survey (NDHS). The sampling frame used for the 2008 NDHS was the Population and Housing Census conducted in 2006. In the 2006 census, Nigeria had four administrative units namely; states, local government areas, localities and enumeration areas. The enumeration areas were the primary sampling unit or cluster. The 2008 NDHS sample was selected using a stratified two-stage cluster design consisting of 888 clusters, 286 in the urban and 602 in the rural areas. A representative sample of 36,800 households was selected, with a minimum target of 950 completed interviews per state. In each state, the number of households was distributed proportionately among the urban and rural areas. A list of households and mapping exercise were carried out in each cluster. The resulting lists of households served as the sampling frame for the selection of households in the second stage. All private households were listed ${ }^{4}$.

\section{Study population}

The study population was currently married women aged 15-49 years women who had received skilled antenatal and delivery care. The secondary data analysis was on 10,052 and 4,590 women who had received skilled antenatal and delivery care respectively.

\section{Study variable}

In the primary survey, respondents were asked where they received antenatal care, as well as who checked them before they were discharged from the health facility after delivery. Two outcome variables were considered: - (1) skilled antenatal care and skilled delivery care.

\section{Receipt of skilled care:}

A respondent was considered to have had skilled antenatal care (ANC), if she had ANC in a public or private hospital at least once during the last pregnancy. She was classified as having had a skilled delivery care, if she was attended to or checked by a doctor, a nurse, or a midwife during labour and after delivery before being discharged from the health facility ${ }^{4}$.

The main explanatory variables were women's:- participation on decision making on her own health, employment status and influence over earnings, earning in relation to partners and attitude towards wife beating. Other important variables were respondents socio demographic characteristics such as age, place of residence, region, educational level, wealth index and parity.

\section{cipation on decision making:}

The 2008 survey asked women whether they were involved in decision making (either by themselves or jointly with their husband), in four areas in which married woman usually makes decisions namely: on he own health care, making major household purchases, making purchases for daily household needs, and visits to her family or relatives ${ }^{4}$. Decisions on daily household purchases is indicative of women's influence over routine household activities, decision on large purchases is suggestive of decision making with partner, while visit to relative is indicative of influence over her social life. In contrast, women's participation in decisions on their own health care is the most likely decision making varable to influence utilization of maternal care services Therefore, it was the decision-making variable focused upon, for which two dichotomous categories of "involved in final decision (alone or jointly)" and "not involved in final decision" (another individual makes the decision) were the possible responses.

Employment status and influence over earnings:

The DHS asked women four questions relating to employment and control over earnings: "Aside from your own housework, are you currently working?"; "Have you done any work in the past 12 months?"; "Are you paid in cash or kind for this work or are you not paid at all?"; and "Who mainly decides how the money you earn will be used?" Answers were categorized into a trichotomous variable: not working, working and had no control over earnings (including those who worked without earning any cash income), and working and had control over earnings. Women who were currently working or who had worked within the 12 months prior to the survey were considered to be working.

\section{Earning in relation to partners}

The relative magnitude of women's earnings compared with their husbands' in the 12 months preceding the 
survey was assessed. Responses were categorised into Data analysis

four namely: wife more than partner, wife less than partner, wife same as husband and husband does not earn.

\section{Attitude towards wife beating:}

The 2008 NDHS collected information on the degree of acceptance of wife beating by asking whether a husband is justified in beating his wife in each of five situations namely: if she burns the food, if she argues with him, if she goes out without telling him, if she neglects the children, and if she refuses to have sex with him.

\section{Socio demographic characteristics:}

Social and demographic characteristics considered in the analysis, included women's age and parity. Because community norms and values influence individual's behavior, the place of residence (urban or rural) and region of residence (north and south) were also assessed. Women's education level was categorized as none, primary, and secondary or higher. Indicators of the household's socioeconomic circumstances included husband's education, as well as a computed wealth index.

The Statistical Package for Social Sciences was used for the analysis ${ }^{24}$. Univariate (frequency distribution), bivariate (chi-square) and multivariate (multiple logistic regression) were done to investigate the association between the dependent and independent variables. The bivariate analysis described the relationship between women's socio demographic variables and their use of skilled antenatal and delivery care. Associations between the indicators of women's household position and the two health care outcomes were also explored. Finally, multivariate regression analysis was done to identify the relationship between the indicators of women's household position and their use of skilled maternal health care. The model controlled for potential confounders including age and parity, residence, education and socioeconomic status. The analysis was done at $5 \%$ level of significance.

\section{Result}

Table 1 shows the socio demographic characteristics of the women who received skilled care. The mean age of the women who received skilled ANC was $29.86+7.01$ years, while for those who received skilled delivery care it was $30.23+6.68$ years. In both groups most of the

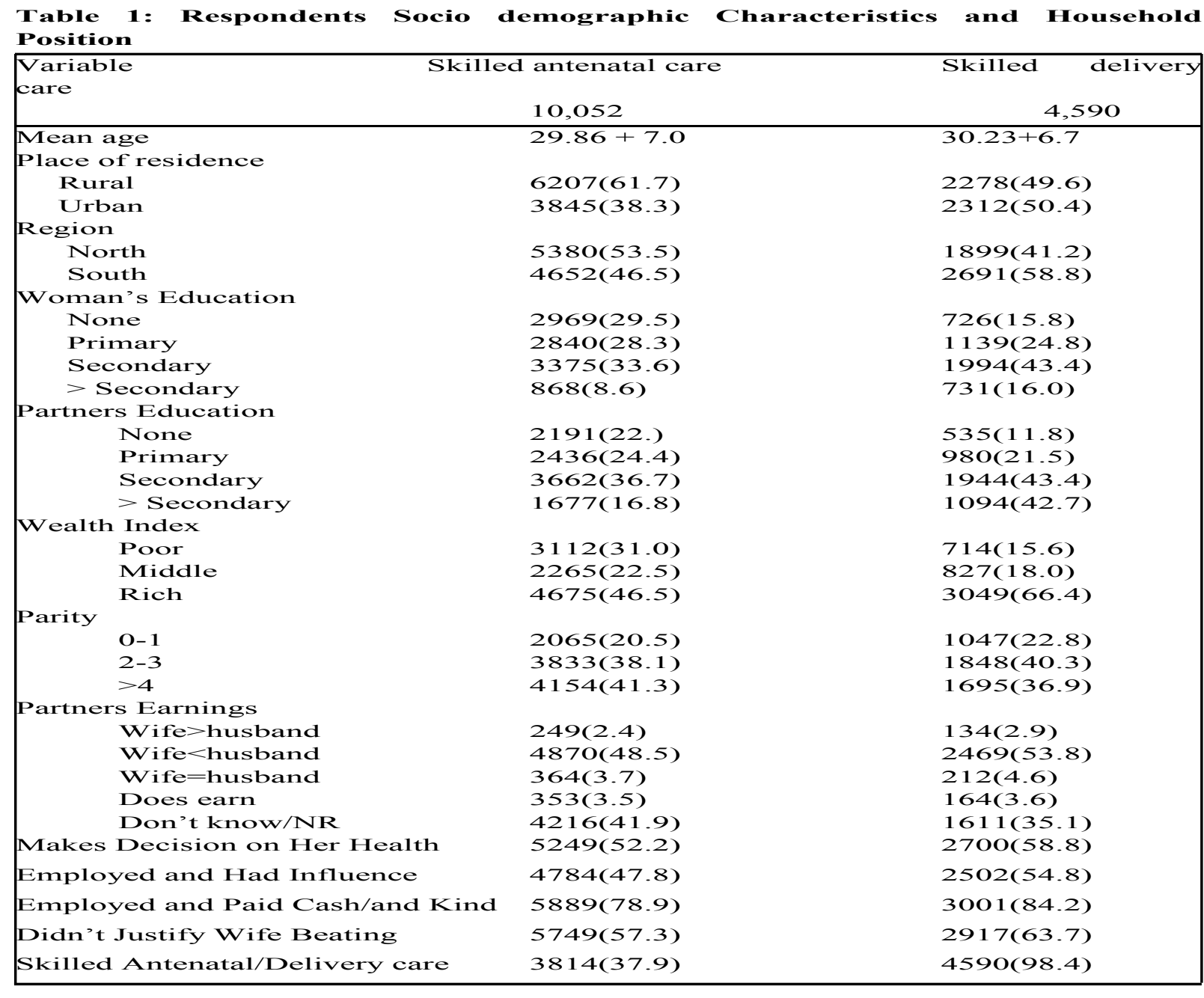

women had secondary education $(33.6 \%$ and $43.4 \%)$ dex. Urban respondents were significantly more likely respectively. Most women earned less than their part- to receive skilled antenatal (aOR 1.37; 95\%CI 1.24ners $(83.4 \%$ and $82.9 \%$ respectively). Many (46.5\% and 1.52$)$ and delivery care (aOR $2.14 ; 95 \%$ CI $1.15-3.98)$ $66.4 \%$ respectively) belonged to the rich wealth index. than those who reside in rural areas. The women from Most (57.3\% and $63.7 \%$ respectively) did not justify the Southern region of the country were less likely to wife beating. Acceptance of wife beating if partner receive skilled antenatal care (aOR 0.53 ; 95\%CI 0.47 burns the food, argues with him, goes out without tell- 0.60) compared to those from the north, but more ing him, neglects the children and refuses to have sex likely to receive skilled delivery care (OR 2.10; $95 \% \mathrm{CI}$ with him was by $16.2 \%, 27.6 \%, 32.2 \%, 30.5 \%, 25.3 \% \quad 1.32-3.36$ ). The respondents with secondary or tertiary respectively. Only $38.0 \%$ received skilled antenatal care education were more likely (aOR 1.19; 95\%CI 1.03 while $98 \%$ received skilled delivery care.

1.37) to receive skilled antenatal care, compared with Table 2 shows the socio demographic characteristics in- those with primary (aOR 1.03; 95\% CI 0.90-1.18) and fluencing women's receipt of skilled antenatal care and no education. Also, women with secondary or tertiary delivery care. Variables found to be significantly associ- education were (OR 3.56; 95\%CI 2.06-6.18) significantated with the receipt of skilled antenatal care were place ly more likely to have skilled delivery care than those of residence, region, level of education and wealth in- with primary (OR 1.81; 95\%CI 1.01-3.24) and with no

Table 2: Regression analysis: receiving skilled antenatal and delivery care on the

\begin{tabular}{|c|c|c|c|c|}
\hline \multirow[t]{2}{*}{ Variables } & \multicolumn{2}{|c|}{ Skilled antenatal care } & \multicolumn{2}{|c|}{ Skilled delivery care } \\
\hline & $\begin{array}{l}\text { Unadjusted } \\
\text { OR (95\% CI) }\end{array}$ & $\begin{array}{l}\text { Adjusted OR } \\
\text { (95\% CI) }\end{array}$ & \begin{tabular}{|l|} 
Unadjusted \\
OR (95\% CI)
\end{tabular} & $\begin{array}{l}\text { Adjusted OR } \\
\text { (95\% CI) }\end{array}$ \\
\hline $\begin{array}{l}\text { Age group (yrs) } \\
<30 \\
30-39 \\
40-49 \\
\end{array}$ & $\begin{array}{l}1 \\
1.04(0.95-1.13) \\
1.03(0.90-1.17)\end{array}$ & & $\begin{array}{l}1 \\
1.42(0.85-2.36) \\
0.86(0.43-1.73) \\
\end{array}$ & \\
\hline $\begin{array}{l}\text { Residence } \\
\text { Rural } \\
\text { Urban }\end{array}$ & $\begin{array}{l}1 \\
1.71(1.57-1.85)\end{array}$ & $\begin{array}{l}1 \\
1.37(1.24-1.52)\end{array}$ & \begin{tabular}{|l|}
1 \\
3.47(2.01-5.97)
\end{tabular} & $\begin{array}{l}1 \\
2.14(1.15-3.98)\end{array}$ \\
\hline $\begin{array}{c}\text { Region } \\
\text { North } \\
\text { South }\end{array}$ & $\begin{array}{l}1 \\
0.49(0.45-0.53)\end{array}$ & 1 0.53(0.47-0.60) & \begin{tabular}{|l|}
1 \\
$2.10(1.32-3.36)$ \\
\end{tabular} & $\begin{array}{l}1 \\
1.49(0.83-2.69)\end{array}$ \\
\hline $\begin{array}{l}\text { Education } \\
\text { None } \\
\text { Primary } \\
\geq \text { Secondary }\end{array}$ & $\begin{array}{l}1 \\
0.74(0.67-0.82) \\
0.93(0.84-1.02)\end{array}$ & $\begin{array}{l}1 \\
1.03(0.90-1.18) \\
1.19(1.03-1.37)\end{array}$ & \begin{tabular}{|l|}
1 \\
$1.81(1.01-3.24)$ \\
$3.56(2.06-6.18)$
\end{tabular} & $\begin{array}{l}1 \\
1.43(0.78-2.65) \\
1.73(0.92-3.27)\end{array}$ \\
\hline $\begin{array}{l}\text { Partner's educ } \\
\text { None } \\
\text { Primary } \\
\geq \text { Secondary }\end{array}$ & $\begin{array}{l}1 \\
0.66(0.58-0.74) \\
1.02(0.92-1.13)\end{array}$ & $\begin{array}{l}1 \\
1 \\
0.85(0.74-0.98) \\
1.05(0.91-1.20)\end{array}$ & $\begin{array}{l}1 \\
0.96(0.46-2.00) \\
\mathbf{1 . 5 0}(0.77-2.93)\end{array}$ & \\
\hline $\begin{array}{l}\text { Ethnicity } \\
\text { Hausa } \\
\text { Igbo } \\
\text { Yoruba } \\
\text { Others } \\
\end{array}$ & $\begin{array}{l} \\
1 \\
0.20(0.17-0.23) \\
0.31(0.27-0.36) \\
0.33(0.29-0.37) \\
\end{array}$ & $\begin{array}{l} \\
1 \\
0.26(0.21-0.32) \\
0.35(0.30-0.42) \\
0.38(0.34-0.44) \\
\end{array}$ & \begin{tabular}{|l|}
1 \\
$2.75(0.83-9.06)$ \\
$1.10(0.43-2.78)$ \\
$0.70(0.29-1.64)$ \\
\end{tabular} & $\begin{array}{l}1 \\
1.16(0.31-4.39) \\
0.49(0.17-1.42) \\
0.62(0.25-1.52)\end{array}$ \\
\hline $\begin{array}{l}\text { Wealth index } \\
\text { Poor } \\
\text { Middle } \\
\text { Rich } \\
\end{array}$ & $\begin{array}{l}1 \\
1.21(1.08-1.36) \\
1.66(1.51-1.83)\end{array}$ & $\begin{array}{l}1 \\
1.27(1.12-1.43) \\
1.86(1.63-2.12)\end{array}$ & \begin{tabular}{|l}
1 \\
$1.74(0.96-3.14)$ \\
$\mathbf{4 . 5 7 ( 2 . 6 8 - 7 . 8 0})$
\end{tabular} & $\begin{array}{l}1 \\
1.38(0.76-2.52) \\
\mathbf{2 . 0 7 ( 1 . 0 8 - 3 . 9 6 )}\end{array}$ \\
\hline $\begin{array}{l}\text { Parity } \\
\text { One child/None } \\
2-3 \text { children } \\
\geq 4 \text { children }\end{array}$ & $\begin{array}{l}1 \\
1.00(0.90-1.12) \\
1.04(0.93-1.16)\end{array}$ & & \begin{tabular}{|l|}
1 \\
$1.78(0.95-3.32)$ \\
$0.95(0.55-1.66)$
\end{tabular} & \\
\hline
\end{tabular}

education. Partners with secondary or tertiary education were also more likely to have wives who receive the were significantly more likely than the poor to have and OR 1.50; 95\% CI 0.77-2.93). As regards wealth in- skilled delivery care (aOR 2.07; 95\% CI 1.08-3.96).

dex, the rich wealth quintile (aOR 1.86; 95\%CI 1.63

2.12), compared with middle class (aOR 1.27; 95\%CI As shown in Table 3, women who could make decision on their health (either jointly or alone) (35\%) compared 
Table 3: Regression analysis: skilled antenatal and delivery care on the women's

\begin{tabular}{|c|c|c|c|c|}
\hline \multirow[t]{2}{*}{ Variables } & \multicolumn{2}{|c|}{ Skilled antenatal care } & \multicolumn{2}{|c|}{ Skilled delivery care) } \\
\hline & \begin{tabular}{|l|} 
Unadjusted \\
OR (95\% CI) \\
\end{tabular} & \begin{tabular}{|l} 
Adjusted OR \\
$\mathbf{9 5 \%} \% \mathrm{CI}$
\end{tabular} & $\begin{array}{l}\text { Unadjusted } \\
\text { OR (95\% CI) } \\
\end{array}$ & \begin{tabular}{|l|}
$\begin{array}{l}\text { Adjusted OR } \\
\text { (95\%CI }\end{array}$ \\
\end{tabular} \\
\hline 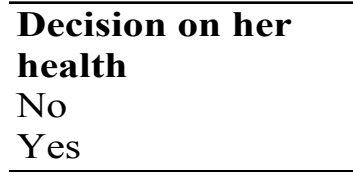 & \begin{tabular}{|l}
1 \\
$\mathbf{1 . 7 8 ( 1 . 7 2 - 1 . 8 5 )}$ \\
\end{tabular} & $\begin{array}{l}1 \\
1.97(1.88-2.06) \\
\end{array}$ & $\begin{array}{l}0 \\
1 \\
1.52(1.02-2.40) \\
\end{array}$ & \\
\hline $\begin{array}{l}\text { Employment and } \\
\text { influence over } \\
\text { earnings } \\
\text { Not employed } \\
\text { Employed and no } \\
\text { influence } \\
\text { Employed and had } \\
\text { influence }\end{array}$ & $\begin{array}{l}1 \\
1.73(1.66-2.82) \\
1.91(1.83-2.00)\end{array}$ & \begin{tabular}{|l|}
1 \\
$1.15(1.01-1.30)$ \\
$1.11(1.00-1.23)$
\end{tabular} & $\begin{array}{l}1 \\
1.37(0.70-2.68) \\
1.32(0.77-2.23)\end{array}$ & \\
\hline $\begin{array}{l}\text { Wife's beating } \\
\text { justified for at } \\
\text { least one reason } \\
\text { No } \\
\text { Yes } \\
\end{array}$ & \begin{tabular}{|l}
1 \\
$0.92(0.85-0.99)$
\end{tabular} & & $\begin{array}{l}1 \\
0.41(0.25-0.64)\end{array}$ & $\begin{array}{l}1 \\
0.54(0.33-0.87)\end{array}$ \\
\hline $\begin{array}{l}\text { Type of earnings } \\
\text { for work } \\
\text { Not paid and paid } \\
\text { in kind only } \\
\text { Paid in cash and } \\
\text { kind }\end{array}$ & $\begin{array}{l}1 \\
1.65(1.46-1.86)\end{array}$ & & $\begin{array}{l}1 \\
1.49(0.80-2.76)\end{array}$ & \\
\hline $\begin{array}{l}\text { Partner's earnings } \\
\text { Wife }>\text { husband } \\
\text { Wife }<\text { husband } \\
\text { Wife }=\text { husband } \\
\text { Doesn't bring cash }\end{array}$ & \begin{tabular}{|l|}
1 \\
$1.17(0.90-1.52)$ \\
$1.06(0.76-1.48)$ \\
$\mathbf{1 . 5 3 ( 1 . 0 9 - 2 . 1 3 )}$
\end{tabular} & & $\begin{array}{l}1 \\
0.92(0.22-3.85) \\
1.06(0.17-6.40) \\
\mathbf{1 . 2 3 ( 0 . 1 7 - 8 . 8 3 )}\end{array}$ & \\
\hline
\end{tabular}

to those who had decisions made by husband alone 2.76). Also women who justified wife beating were sigor others, were less likely (OR $0.97 ; 95 \% \mathrm{CI} 0.88-1.06$ ) nificantly less likely (aOR $0.54,95 \% \mathrm{CI} 0.33-0.87$ ) to reto have skilled antenatal care. Compared to the unem- cieve skilled delivery care.

ployed, employed women who had no influence (aOR $1.11,95 \%$ CI 1.00-1.23) and employed who had influence over their earnings were more likely (aOR 1.15, $95 \%$ CI 1.01-1.30) to receive skilled care Women who justified wife beating were less likely to receive care (OR $0.92 ; 95 \%$ CI $0.85-1.00)$. When the woman earned more than her partner she was less likely to receive skilled antenatal care.

Although not statistically significant, women who were able to make decisions on their own health were more likely (OR 1.52; 95\%CI 0.96-2.40) to receive skilled delivery care than those who could not. Women who worked and received their payment in cash were more likely to have skilled delivery care than those not paid or who were paid only in kind (OR 1.49, 95\%CI 0.80 Nigeria and the changes required in Nigerian women's position needed to improve health care use.
The uptake of skilled health care depends on both the perceived need for demand (which implies the recognition that available services are valuable and appropriate) and the ability to act on that demand. Gender relations may affect these factors ${ }^{25}$. Although other elements, largely unrelated to gender relations may exert a critical influence on demand for health services and the ability to act. Also, increases in the uptake of reproductive health services may occur in the absence of any significant change in women's household position such as occurs with government policy changes on free, subsidized health care, or the distribution incentives or commodities with care $\mathrm{e}^{16,17,26}$.

Women's employment improved use of maternal health care. Having influence over money earned further improved use of skilled antenatal and delivery care. Thus even if women work but have no control over the use of their earnings, they were less likely to receive skilled antenatal or delivery care than when they did. This is not surprising as working women with access and influence over their earnings are expected to be able to utilise their funds on their own health. Working women are also more likely to be exposed to health information at their places of work. This should lead to improved use of skilled services by increasing both the demand and eventually the (supply) quality of service provided

${ }^{25}$. However it is appreciated that sometimes working women experience time constraints that reduce their opportunities for receiving antenatal care ${ }^{27}$.

Women who did not accept physical intimate violence were more likely to recieve both antenatal and delivery care. This probably indicates that these women rejected the conduct and beliefs that places them at a low status relative to men and did not accept violence as a means to resolve conflict ${ }^{4,28}$. The danger with agreeing that wife beating is acceptable is that it promotes the perpetration of family and community violence. Also women who hold such beliefs are less likely to report acts of violence or seek care from a health facility following abuse $^{29,30}$. They are also less likely to go to a health facility for skilled maternal health care services ${ }^{29,30}$.

In light of this association between attitudes to violence and the use of skilled health care, it is unsurprising that the ability to make decisions was associated with improved use of skilled maternity care. However, the an's involvement in decision making may alone not as influential as decisions by both herself and her husband, however this assumption needs to be further explored. In Nigeria like many countries of sub Sahara Africa, decisions regarding the management of pregnancy and child care are often within the purview of husbands, older female relatives, usually mother-in-laws and grandmothers who often wield so much power and are able to influence the type of care received by young pregnant mothers ${ }^{25}$. Also the culture is patriarchal and husbands are believed to own the children ${ }^{31}$. Women tend to exert influence only in subtle non-confrontational ways ${ }^{31}$. When women are unable to make decisions they are also more vulnerable to abuse from health care providers, and there is empirical evidence linking women's lack of autonomy and empowerment to disrespectful birth care ${ }^{32}$. Hence, greater attention should be directed to the ways in which reproductive health decision making involves partners who usually wield much power over mother's choice of maternal health services.

Women's economic dependency has long been understood to be a major factor in structuring inequalities between men and women. Hence, control over financial resources is often considered a central dimension when measuring women's household position. Accessing maternal health care requires financial outlay (for transporation, medicines and, in some cases, consultation), thus a woman's ability to pay for these services with her own earnings is an important determinant of access ${ }^{29,30}$. Although it appeared that when women earned better than their partners they were unable to take adequate care of themselves, probably as a result of the huge financial burden they had to bear. This suggests that a woman's ability to improve her health may not only depend on her employment status and influence over her earnings, but may also depend on her partner's earnings. However we did not obtain a clear picture and recommend further studies on this aspect of women's status.

The relationship between women's education and use of maternal health care draws attention to how the broader gender system, operating beyond the household, may affect care. A number of routes of causation might explain this effect. Earlier work had suggested that it may be due at least in part to a fostering of new values and attitudes that are favorable to the use of modern health care $^{31}$. Also, it is recognized that edu- 
cation may impart feelings of self-worth and self-confidence, which some have noted are more important in bringing about changes in health-related behavior. In addition to increasing the likelihood that women will value and desire skilled care, education may strengthen also reduce the power differential between providers and clients and lower women's reluctance to seek care ${ }^{32}$.

Education may also work through increased discussion and decision making between husbands and wives ${ }^{25,31,32}$

The strength of this study is that it is one of the firs studies to examine the effect of household women's position on the utilization of maternity care services in Africa and its large sample size. Similar studies in other African countries are recommended.

\section{Limitations}

Its limitations lies in the cross sectional nature of the design, hence it was not possible to determine causaa secondary data analysis. In the primary study, some respondents may also have given socially desirable responses on the utilization of maternity services. Despite these limitations, it is clear that gender relations influence the use of maternal health care in different ways. In addition, these findings draw attention to the need to study and probably raise knowledge levels and alter perception of the value of modern preventive health including the value attached to women's health by both pregnant women and their partners. Thus there is the need for research on how attitude affects the demand for maternity care.

\section{Conclusion}

From the forgoing it is clear that gender relations influence the use of maternal health care. Socio cultural factors such as education, residence and region of the country also emerged as an important factor influencing use. Thus in addition to the current strategies being implemented by the federal government, internationa organizations and women's groups to raise the profile of maternal health, the study showed that promoting women's position in the home is crucial to improve utilization of maternity services in Nigeria and probably many other African countries as well. The Millennium Development Goal three is unlikely to be met if all the socio cultural determinants of service uptake are not addressed. Thus interventions that will stop intimate women's ability to act on this demand. Education may tion. Also there were missing key variables as it was partner violence, improve individual and joint decision making between husband-wife and empower women are important efforts that deserve sustained support. These programmes should be targeted especially at poor, unemployed women residing in rural areas. The need for programs that promote schooling for Nigerian girls is again highlighted.

\section{Acknowledgement}

1 am grateful to Macro International USA and the $\mathrm{Na}$ -

tional Population Commission, Nigeria for allowing me to use their data (NDHS 2008) for this study. The results of this study were presented at the 2013 Global Maternal Health Conference in Tanzania.

\section{References}

World Health Organization. Estimates developed by WHOM, UNICEF, UNFPA and The World Bank. Geneva. Trends in maternal mortality: $1990-2008$ World Health Organization 2010, Geneva.

2. World Health Organization. A Joint WHO /UNFPA /UNICEF /World Bank Statement: Reduction of maternal mortality. World Health Organization 1999, Geneva.

3. Zozulya M. Maternal mortality in Nigeria: An indicator of women's status. Consultancy Africa Intelligence 2010. Gender Issues Unit http://www.consultancyafrica.com/index.php (Accessed 11/9/13)

4. National Population Commission [Nigeria] and ICF Macro. Nigeria Demographic and Health Survey 2008. National Population Commission and ICF Macro 2009 Abuja, Nigeria.

5. Khan KS, Wojdyla D, Say L, Gülmezoglu AM, Van Look PF. World Health Organization analysis of causes of maternal death: a systematic review. Lancet 2006

6. Fathalla MF. Human rights aspects of safe motherhood. Best Pract Res Clin Obstet Gynaecol 2006; 20 409-419.

USAID, 2012. Maternal and child health integrated program strategy. http://nigeria.usaid.gov/programs/health-population-and-nutrition/projects/ maternal-and-child-health-intergrated-program-mchi. (Accessed 21/6/2013)

8. Ibeh CC. Is poor maternal mortality index in Nigeria problem of care utilization? A case study of Anambra State. AfrJ Reprod Health 2008;12(2):132-40.

. Fawole AO, Shah A, Fabanwo AO, Adegbola O, 367: 1066-1074.
Adewunmi AA, Eniayewun AB, Dara K, El-Ladan AM, Umezulike AC, Alu FE, Adebayo AA, Obaitan FO, Onala OE, Usman Y, Sullayman AO, Kailani S, Sa'id M. Predictors of maternal mortality in institutional deliveries in Nigeria. Afr Health Sci. 2012; 12(1):32-40.

10. Okereke E, Ahonsi B, Tukur J, Ishaku SM, Oginni AB. Benefits of using magnesium sulphate $\left(\mathrm{MgSO}_{4}\right)$ for eclampsia management and maternal mortality reduction: Lessons from Kano State in Northern Nigeria. BMC Res Notes 2012; 8(5):421.

11. Sørbye IK, Vangen S, Oneko O, Sundby J, Bergsjø P. Caesarean section among referred and self-referred birthing women: a cohort study from a tertiary hospital, north-eastern Tanzania. BMC Pregnancy Childbirth 2011; 28(11):55

12. van den Akker T, van Rhenen J, Mwagomba B, Lommerse K, Vinkhumbo S, van Roosmalen J. Reduction of severe acute maternal morbidity and maternal mortality in Thyolo District, Malawi: The impact of obstetric audit. PLoS One 2011; 6(6):e20776.

13. Govindasamy P, Malhotra A. Women's position and family planning in Egypt. Stud Fam Plann 1996; 27(6):328-40.

Tambashe BOThe impact of women's employment and education on contraceptive use and abortion in Kinshasa, Zaire. Stud Fam Plann. 1994, 25(2):96-110.

15. Agyei WK, Migadde M. Demographic and sociocultural factors influencing contraceptive use in Uganda. Biosoc Sci 1995; 27(1):47-60

16. Tawiah EO. Factors affecting contraceptive use in Ghana. J Biosoc Sci 1997; 29(2): 141-9.

17. Oheneba-Sakyi Y. Determinants of current contraceptive use among Ghanaian women at the highest risk of pregnancy. J Biosoc Sci 1992; 24(4): 463-75.

18. United Nations. The United Nations millennium declaration. The millennium assembly 2000, United Nations, New York.

19. National Population Commission (NPC) 2007. The 2006 National Census Report. National Population Commission, Abuja, Nigeria.

20. Index Mundi, 2013. Nigeria Demographic Profil 2013. Life expectancy at birth. http://www.indexmundi.com/nigeria (Accessed 11/3/2012).

21. Federal Ministry of Health Nigeria/UNICEF 2002. Women and children rights in Nigeria: A wake up call - Situation assessment and analysis. Federal Ministry of Health Abuja, Nigeria.
2. Ministry of Women Affairs (MWA)/ Gender and (GADA) 2009. National gender policy: A simplified version. Ed. Duke SB and Effiong

23. Federal Ministry of Health, 2004. The revised naAbuja, Nigeria.

24. Statistical Package for Social Scientist (SPSS) Inc. SPSS Base 9.0 for Window User's Guide. SPSS Inc. 1998, Chicago.

. Wuruta M, Salway S. Women's position within the household as a determinant of maternal health care use Nepal. Int Fam Plan Perspect. 2006; 32(1):17-27.

26. Bouyou-Akotet MK, Mawili-Mboumba DP, Kombila M. Antenatal care visit attendance, intermittent preventive treatment and bed net use during pregnancy in Gabon. BMC Pregnancy Childbirth 2013; 26 (13):52.

27. Agopian AJ, Lupo PJ, Herdt-Losavio ML, Langlois PH, Rocheleau CM, Mitchell LE; Differences in folic acid use, prenatal care in early pregnancy by occupation. Prev Med. 2012; 55(4): 341-5

28. UNFPA, UNIFEM, Office of the Special Adviser on Gender Issues and Advancement of Women (OSAGI) 2005. Combating Gender based violence: a key to achieving the Millennium Development Goals, New York

29. World Bank. Addressing violence against women in middle and low income countries: A multi sectoral approach. Sector Operational Guide for the World Bank Gender and Development Group 2007, New York.

30. Population Council. Sexual and gender based violence in Africa. Literature review, 2008. Population Council, New York.

31. Fayehun OA, Omololu OO, Isiugo-Abanihe UC Sex of preceding child and birth spacing among Nigerian ethnic groups. Afr J Rep Hlth 2011, 15(2):79-89.

32. Singh K, Bloom S, Haney E, Olorunsaiye C, Brodish P. Gender equality and childbirth in a health facility: Noria and MDG5. Afr J Rep Hith 2012; 16(3):123-9.

33. Ikeako LC, Onah HE, Iloabachie GC. Influence of formal maternal education on the use of maternity services in Enugu, Nigeria. J Obstet Gynaecol 2006; 26(1):30-

34. Olusanya BO, Alakija OP, Inem VA. Non-uptake of facility-based maternity services in an inner-city community in Lagos, Nigeria: an observational study. J Bio-

soc Sci. 2010; 42(3):341-58. 